\title{
Effects of Homogeneous Low Energy Electron Beam Irradiation (HLEBI) on Adhesive Energy of Peeling Resistance of Laminated Sheet with Polyurethane (PU) and Polyethylene Terephthalate (PET)
}

\author{
Sagiri Takase ${ }^{1, *}$, Chisato Kubo ${ }^{1, *}$, Masae Kanda ${ }^{1,2}$, Yoshihito Matsumura ${ }^{1,2}$ and Yoshitake Nishi ${ }^{1,2}$ \\ ${ }^{1}$ Graduate School of Engineering, Tokai University, Hiratsuka 259-1292, Japan \\ ${ }^{2}$ School of Engineering, Tokai University, Hiratsuka 259-1292, Japan
}

2-layer laminated sheets (PU/PET) with Polyurethane (PU) and Polyethylene Terephthalate (PET) were prepared by a new adhesion method, a double-step treatment consisting of applying low dose ( $\leqq 1.72 \mathrm{MGy}$ ) homogeneous low energy electron beam irradiation (HLEBI) prior to hot-press under $3 \mathrm{MPa}$ and $348 \mathrm{~K}$. Although the weak hot-press adhesion of the PU/PET was observed without HLEBI, the new adhesion mostly raised the bonding energy as evidenced by the mean adhesive energy of peeling resistance $\left({ }^{\circ} E_{\mathrm{p}}\right)$. Based on the 3 -parameter Weibull equation, the lowest ${ }^{\circ} E_{\mathrm{p}}$ value at peeling probability $\left(P_{\mathrm{p}}\right)$ of zero $\left(E_{\mathrm{s}}\right)$ could be estimated. An increasing trend in $E_{\mathrm{s}}$ occurred by the double-step treatment applying HLEBI up to $1.29 \mathrm{MGy}$ reaching a maximum at $1.83 \mathrm{~kJ} \cdot \mathrm{m}^{-1}$, improving the safety level without radiation damage. When HLEBI cut the chemical bonds in PU and generated terminated atoms with dangling bonds, they probably induced the chemical bonding. Therefore, increasing adhesion energy between the laminated sheets could be explained. [doi:10.2320/matertrans.M2015478]

(Received December 25, 2015; Accepted March 7, 2016; Published April 8, 2016)

Keywords: joint, adhesion, electron beam, irradiation, polyurethane (PU), polyethylene terephthalate (PET)

\section{Introduction}

Joining polymers has extensive application hence advancements in techniques are always highly sought after. Polyurethane (PU) is one of the most versatile materials in the world today. Their many uses range from flexible foam in upholstered furniture, to rigid foam as insulation in walls, roofs and appliances, to thermoplastic pure PU used in medical devices and footwear, to coatings, adhesives, sealants and elastomers used on floors and automotive interiors. ${ }^{1)}$ PET have a reputation of being able to gas barrier property and insulation, but difficult adhesives. In other words, it indicates that we can projected use in the semiconductor field.

The adhesion method to prepare 2-layer laminated sheets (PU/PET) with PU and PET is important technology to be utilized for biomedical application. However, no one has been reported. The PU/PET adhesion by both hot-press and its strengthening method treated by homogeneous low energy electron beam irradiation (HLEBI) prior to hot-press has been found. HLEBI improves the mist resistance and wetting of inorganic materials, ${ }^{2)}$ and increases polymer adhering to glass fibers raising impact strength in GFRP. ${ }^{3)}$

Applying surface treatment of low dose of electron beam irradiation on the order of 0.01 to $1 \mathrm{MGy}$ has been gaining momentum as a successful method to adhere polymeric materials without the use of adhesive. Polyimide/polytetrafluoroethylene (PI/PTFE) layered films have been successfully fabricated by Homogeneous low energy electron beam irradiation (HLEBI) $;{ }^{4)}$ while applying 0.50 MGy HLEBI dose increased adhesive bond strength between PET films and acrylic adhesive. ${ }^{5)}$ HLEBI has been found to increase adhesive mechanical properties of polymer-polymer joints for biomedical applications of PDMS (polydimethylsilozane)/PTFE, ${ }^{6)}$ PDMS/ PP (polypropylene) ${ }^{7)}$ and create strong adhesion in the difficult to bond PTFE/PE (polyethylene). ${ }^{8)}$
Improvements are mainly caused by the irradiation with the formation of dangling bonds at terminated atoms in polymers. ${ }^{9)}$ Dangling bonds enhance the surface energy, which is probably the mechanism for joining the different polymers. ${ }^{10)}$ When active free electrons on PU and PET surface act as bonding electrons like dangling bonds of terminated atoms in polymer, chemical bonds and intermolecular attractive force are probably generated, as shown in Fig. 1. Thus, rapid and strong adhesion of PU/PET by using HLEBI prior to hotpress can be expected.

Therefore, the effects of HLEBI prior to hot-press lamination on the adhesive energy of peeling resistance of bio-adaptable and high strength PU/PET laminated sheets of PU/PET have been investigated.

\section{Experimental Procedure}

\subsection{Preparation of PU/PET laminated sheets}

Composite sheets were constructed with PET (polyethylene terephthalate $)$ film $(10 \times 40 \times 0.50 \mathrm{~mm}$, Teijin $\mu$ Tetoron $\mu$ Film, Teijin DuPont Films, Japan) and PU (10 mm $\times$ $40 \mathrm{~mm} \times 0.07 \mathrm{~mm}$ ) film. Pure PU film was prepared by a simple solution cast method. ${ }^{11-14)} 25$ gram of PU granules (Noveon Estane 58888 NAT021, Lubrizol Corporation, Wickliffe, OH, USA) was dissolved in approximately $100 \mathrm{ml}$ of $\mathrm{N}, \mathrm{N}$-dimethylformamide (DMF) at $413 \mathrm{~K}$ for $3 \mathrm{~h}$. The solution was poured onto a glass plate and dried at $333 \mathrm{~K}$ at atmospheric pressure for one day. The obtained films were removed from the plate with ethanol. Subsequently, they were placed in a ventilated oven at $403 \mathrm{~K}$ for $4 \mathrm{~h}$ in order to eliminate residual solvent. The thicknesses of the films were about $70 \mu \mathrm{m}$. The glass transition temperatures $\left(T_{\mathrm{g}}\right)$ of PET is $353 \mathrm{~K}$, and PU is $228 \mathrm{~K}$ respectively. ${ }^{15}$ )

\subsection{Homogeneous low energy electron beam Irradiation (HLEBI)}

The PU/PET laminated sheets was irradiated by using an 

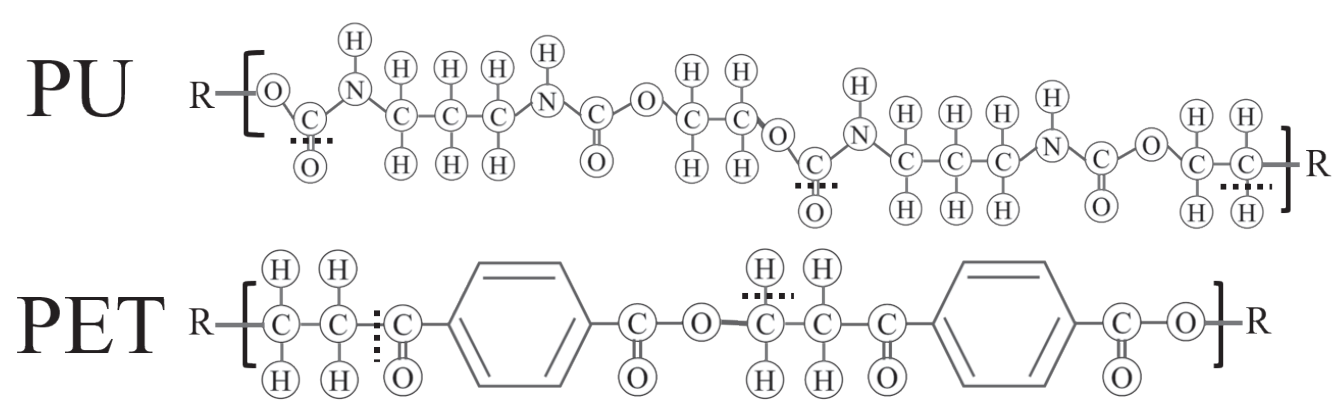

a) Before lamination

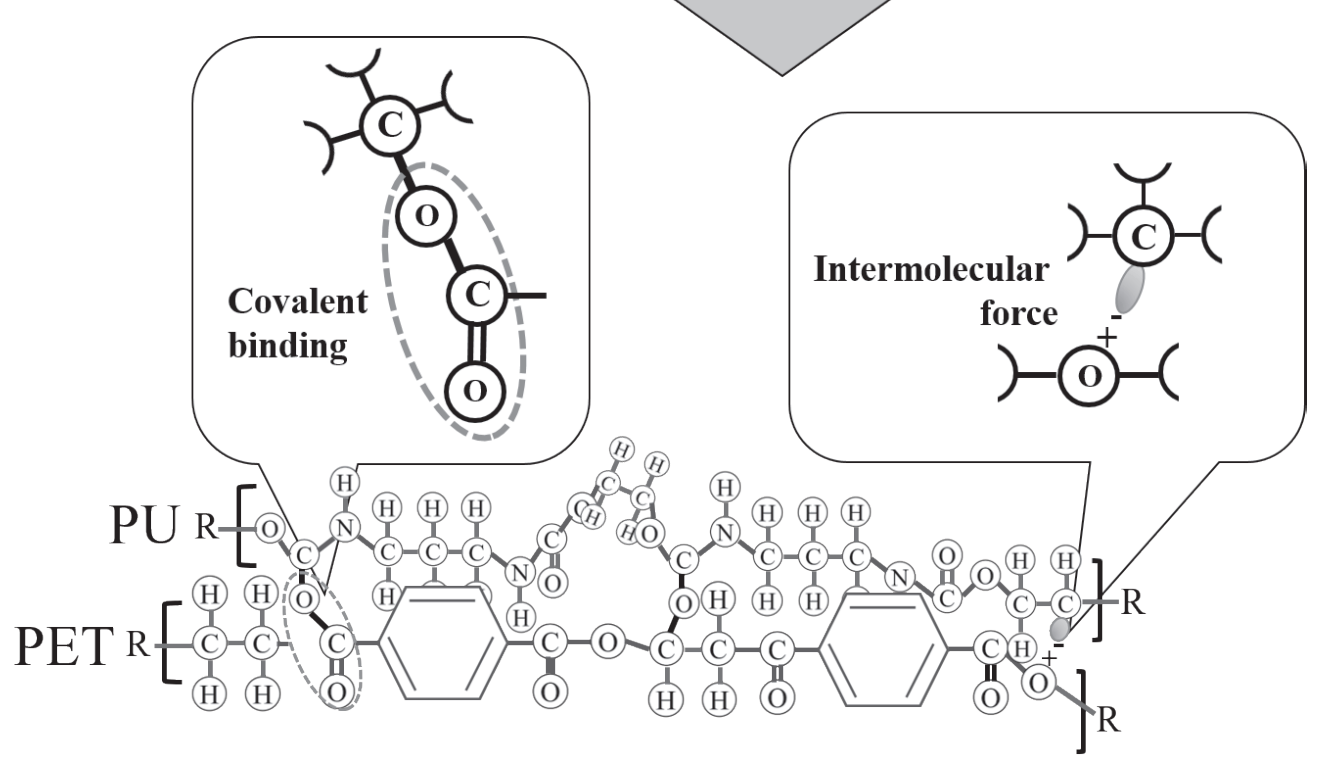

b) After lamination

Fig. 1 Schematic illustration of chemical and intermolecular bonding sites at interface between PU and PET before and after lamination.

electron-curtain processor (Type CB250/15/10mA, Energy Science Inc., Woburn, MA, Iwasaki Electric Group Co. Ltd. Tokyo). ${ }^{8,16-19)}$ The specimen was homogeneously irradiated with the sheet HLEBI with low energy through a titanium thin film window attached to a $240 \mathrm{~mm}$ diameter vacuum chamber. A tungsten filament in a vacuum is used to generate the electron beam at a low energy (acceleration potential, $V$ : $\mathrm{kV})$, of $170 \mathrm{keV}$ and irradiating current density $\left(I, \mathrm{~A} / \mathrm{m}^{2}\right)$ of $0.089 \mathrm{~A} / \mathrm{m}^{2}$.

Although the sheet electron beam generation is in a vacuum, the irradiated sample has been kept under protective nitrogen at atmospheric pressure. The distance between sample and window is $35 \mathrm{~mm}$. To prevent oxidation, the samples are kept in a protective atmosphere of nitrogen gas with a residual concentration of oxygen below $400 \mathrm{ppm}$. The flow rate of nitrogen gas is $1.5 \mathrm{~L} / \mathrm{s}$ at $0.1 \mathrm{MPa}$ nitrogen gas pressure.

The absorbed dose is controlled by the integrated irradiation time in each of the samples. Here, absorbed dose is corrected from irradiation dose by using an FWT nylon dosimeter of RCD radiometer film (FWT-60-00: Far West Technology, Inc. 330-D South Kellogg Goleta, California 93117, USA) with an irradiation reader (FWT-92D: Far West
Technology, Inc. 330-D South Kellogg Goleta, California 93117, USA). The absorbed dose corresponded to irradiation dose is $0.0432 \mathrm{MGy}$ at each irradiation, which is applied for only a short time $(0.23 \mathrm{~s})$ to avoid excessive heating of the sample; the temperature of the sample surface remains below $323 \mathrm{~K}$ just after irradiation. The sample in the aluminum plate holder $(0.15 \mathrm{~m} \times 0.15 \mathrm{~m})$ is transported on a conveyor at a speed of $9.56 \mathrm{~m} / \mathrm{min}$. The sheet HLEBI is applied intermittently. Repeated irradiations to both side surfaces of the samples are used to increase the total irradiation dose. The interval between the end of one period of irradiation and the start of the next operation is $30 \mathrm{~s}$. When the irradiation current ( $I$, $\mathrm{mA})$, the conveyor speed $(S, \mathrm{~m} / \mathrm{min})$ and number of irradiations $(N)$ are determined, the irradiated dosage is proportional to the yield value from the irradiation current $(I, \mathrm{~mA})$, the conveyor speed $(S, \mathrm{~m} / \mathrm{min})$, and number of irradiations $(N)$.

Based on the density $\left(\rho: \mathrm{kg} \cdot \mathrm{m}^{-3}\right)$ and irradiation voltage at the specimen surface $(V: \mathrm{kV})$, the penetration depth $\left(D_{\mathrm{th}}: \mathrm{m}\right)$ of HLEBI is expressed by the following equation. ${ }^{20)}$

$$
D_{\text {th }}=66.7 V^{5 / 3} / \rho
$$

Specimen surface electrical potential $(V)$ was mainly reduced 
going through the Ti window $\left(\Delta V_{\mathrm{Ti}}\right)$ and $\mathrm{N}_{2}$ gas atmosphere $\left(\Delta V_{\mathrm{N} 2}\right)$.

$$
V=170 \mathrm{keV}-\Delta V_{\mathrm{Ti}}-\Delta V_{\mathrm{N} 2}
$$

Based on eq. (2), the dropped potential values, $\Delta V_{\mathrm{Ti}}$ and $\Delta V_{\mathrm{N} 2}$ are estimated from the acceleration potential $(170 \mathrm{keV})$, the $10 \mu \mathrm{m}$ thickness $\left(T_{\mathrm{Ti}}\right)$ of the titanium window (density: $\left.4540 \mathrm{~kg} \cdot \mathrm{m}^{-3}\right)$, and the $35 \mathrm{~mm}$ distance between the sample and the window $\left(T_{\mathrm{N} 2}\right)$ in the $\mathrm{N}_{2}$ gas atmosphere (density: $\left.\rho_{\mathrm{N} 2}=1.13 \mathrm{~kg} \cdot \mathrm{m}^{-3}\right)$.

$$
\begin{aligned}
V_{\mathrm{Ti}}= & \left(T_{\mathrm{Ti}} / \mathrm{D}_{\mathrm{thTi}}\right) \times 170 \mathrm{keV}=T_{\mathrm{Ti}} \rho_{\mathrm{Ti}} /\left[66.7 \times(170 \mathrm{keV})^{2 / 3}\right] \\
= & \left(10^{-5} \mathrm{~m}\right) \times\left(4540 \mathrm{kgm}^{-3}\right) /\left[66.7 \times(170 \mathrm{keV})^{2 / 3}\right] \\
= & 22.2 \mathrm{keV} \\
\Delta V_{\mathrm{N} 2} & =\left(T_{\mathrm{N} 2} / \mathrm{D}_{\mathrm{thiN} 2}\right) \times V_{\mathrm{Ti}}=T_{\mathrm{N} 2} \rho_{\mathrm{N} 2} /\left[66.7 \times\left(V_{\mathrm{Ti}}\right)^{2 / 3}\right] \\
& =\left(35 \times 10^{-3} \mathrm{~m}\right) \times\left(1.13 \mathrm{kgm}^{-3}\right) /\left[66.7 \times(170 \mathrm{keV})^{2 / 3}\right]
\end{aligned}
$$

Since the dropped potential values are 22.2 and $18.2 \mathrm{keV}$, the specimen surface electrical potential, $V$ is $129.6 \mathrm{keV}$ as follows.

$$
V=170 \mathrm{keV}-22.2 \mathrm{keV}-18.2 \mathrm{keV}=129.6 \mathrm{keV}
$$

Given typical density of PU is $1130 \mathrm{~kg} \cdot \mathrm{m}^{-3}$, the HLEBI depth into the PU film estimated from eq. (1) is $D_{\text {th }}=192 \mu \mathrm{m}$, more than four times larger than the PU thickness of $70 \mu \mathrm{m}$, hence the HLEBI penetrated through the entire thickness.

\section{$2.390^{\circ}$-peeling test}

Composite samples after hot-press under $3 \mathrm{MPa}$ at $348 \mathrm{~K}$ were prepared for the $90^{\circ}$-peeling test to evaluate the influence of HLEBI on the mean adhesive energy of peeling resistance $\left({ }^{\circ} E_{\mathrm{p}}\right)$, as shown in Fig. 2. Peeling adhesive energy $\left(E_{\mathrm{p}}\right)$ vs. peeling distance $\left(d_{\mathrm{p}}\right)$ curves were obtained by using a micro-load tensile tester (F-S Master-1K-2N, IMADA Co. Ltd., Japan) with a strain rate of $10 \mathrm{~mm} / \mathrm{min}^{6}{ }^{6}$ Since the unit of the $E_{\mathrm{p}}$ was $\mathrm{kJ} \cdot \mathrm{m}^{-1}$, the ${ }^{\circ} E_{\mathrm{p}}$ was used instead of the adhesive strength, whose units should be $\mathrm{kJ} \cdot \mathrm{m}^{-2}$. The sample condition of tensile test was as follows:

(1) The vertical length from the peeling contact point to the end of the sample was $5 \mathrm{~mm}$.

(2) The $E_{\mathrm{p}}$ was determined by using micro-load tensile tester. The ${ }^{\mathrm{o}} E_{\mathrm{p}}$ was estimated by the peeling load and experimental peeling width and length of 10 and $35 \mathrm{~mm}$, respectively. The initial distance before peeling $\left(d_{\mathrm{i}}\right)$ was defined at the start point of peeling energy, which corresponds to the start point of the first relaxation. The $d_{\mathrm{i}}$ value is $\sim 1 \mathrm{~mm}$.
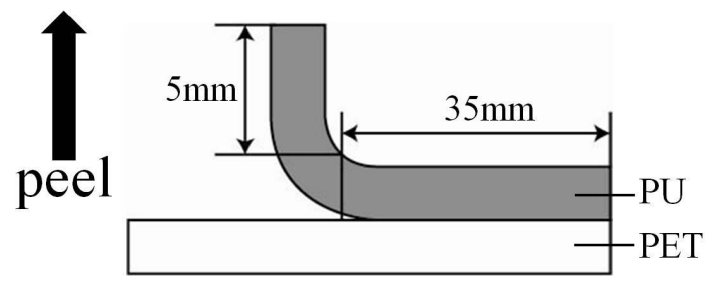

Fig. 2 Schematic diagram of $90^{\circ}$-Peeling test of the PU/PET laminate sheet.

\subsection{X-ray photoelectron spectrometer (XPS) measure- ments}

X-ray photoelectron spectrometer (XPS: Quantum 2000, ULVAC Co., JAPAN) ${ }^{6}$ ) was used for surface analysis of peeled 1.29 MGy HLEBI PU film and PET film. Both PU and PET films contain elements $\mathrm{C}, \mathrm{O}$ and $\mathrm{N}$. Narrow scans for the $\mathrm{C}(1 \mathrm{~s}), \mathrm{O}(1 \mathrm{~s})$ and $\mathrm{N}(1 \mathrm{~s})$ signals from the PU film and PET film surfaces were detected by the XPS.

\section{Results}

\subsection{Peeling load $\left(L_{\mathrm{p}}\right)$ - peeling distance $\left(d_{\mathrm{p}}\right)$ curve}

Figure 3 shows a comparison of $L_{\mathrm{p}}(\mathrm{N})$ vs. peeling distance, $d_{\mathrm{p}}(\mathrm{mm})$ curves between HLEBI and untreated PU/ PET laminated sheets at median accumulative probability of peeling energy, $P_{\mathrm{p}}=0.50$. Although without HLEBI a large peeling load of peeling resistance in the PU/PET laminated sheets could not be obtained, by applying HLEBI at 1.29 MGy the peeling load, $L_{\mathrm{p}}$ is significantly increased $(\sim 1.9 \mathrm{~N})$ over the low value of the untreated $(\sim 0.20 \mathrm{~N})$. The 1.29 MGy-HLEBI therefore laminates the PU with PET, generating the higher peeling resistance. Based on the optical scale observation, the fracture can be seen to always occur at the interface.

\subsection{Adhesive energy of peeling resistance $\left({ }^{\circ} E_{\mathrm{p}}\right)$ as a func- tion of peeling probability $\left(\boldsymbol{P}_{\mathbf{p}}\right)$}

Figure 4 plots the relationships between the adhesive energy of peeling resistance $\left({ }^{\circ} E_{\mathrm{p}}\right)$ and cumulative probability of peeling $\left(P_{\mathrm{p}}\right)$ of the PU/PET laminated sheets for the untreated and HLEBI-treated. Applying 1.29 MGy HLEBI gives the highest ${ }^{\circ} E_{\mathrm{p}}$ values, particularly above $P_{\mathrm{p}}>0.4$. In high $P_{\mathrm{p}}$ $\left(P_{\mathrm{p}}=0.94\right)$, untreated samples at $1.73 \mathrm{~kJ} \cdot \mathrm{m}^{-1}, 1.29$ MGy-HLEBI samples at $7.65 \mathrm{~kJ} \cdot \mathrm{m}^{-1}$. 1.29 MGy-HLEBI samples are about 4.4 times of untreated samples. In high $P_{\mathrm{p}}\left(P_{\mathrm{p}}=0.94\right)$, untreated samples at $0.51 \mathrm{~kJ} \cdot \mathrm{m}^{-1}, 1.29 \mathrm{MGy}$-HLEBI samples at $1.56 \mathrm{~kJ} \cdot \mathrm{m}^{-1}$. 1.29 MGy-HLEBI samples are about 3.1 times of untreated samples. In median $P_{\mathrm{p}}\left(P_{\mathrm{p}}=0.50\right)$, untreated samples at $0.84 \mathrm{~kJ} \cdot \mathrm{m}^{-1}, 1.29 \mathrm{MGy}$-HLEBI samples at

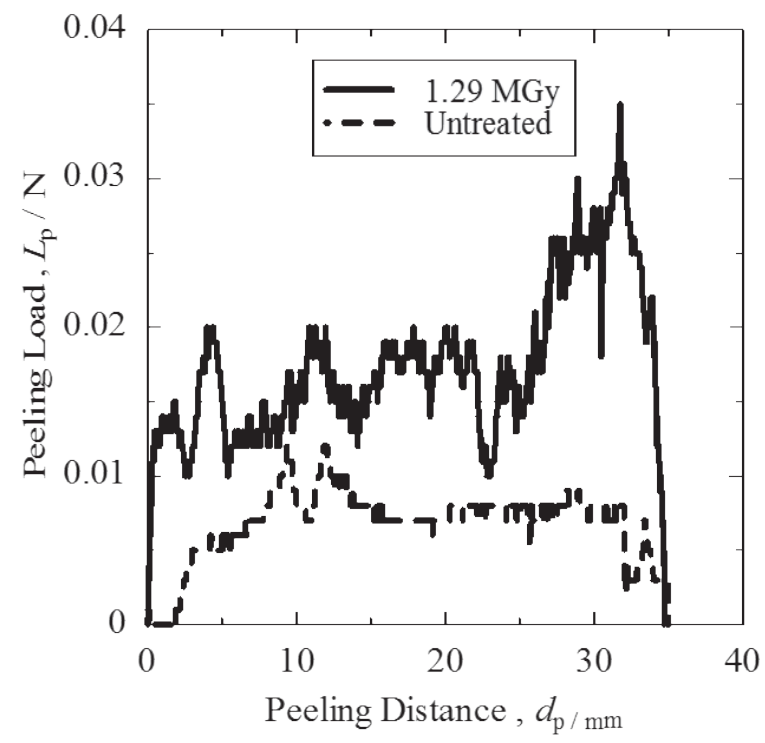

Fig. 3 Peeling load $\left(L_{\mathrm{p}}\right)$ - peeling distance $\left(d_{\mathrm{p}}\right)$ curves of PU/PET laminated sheets before and after 1.29 MGy-HLEBI at $P_{\mathrm{p}}$ of 0.94 . 


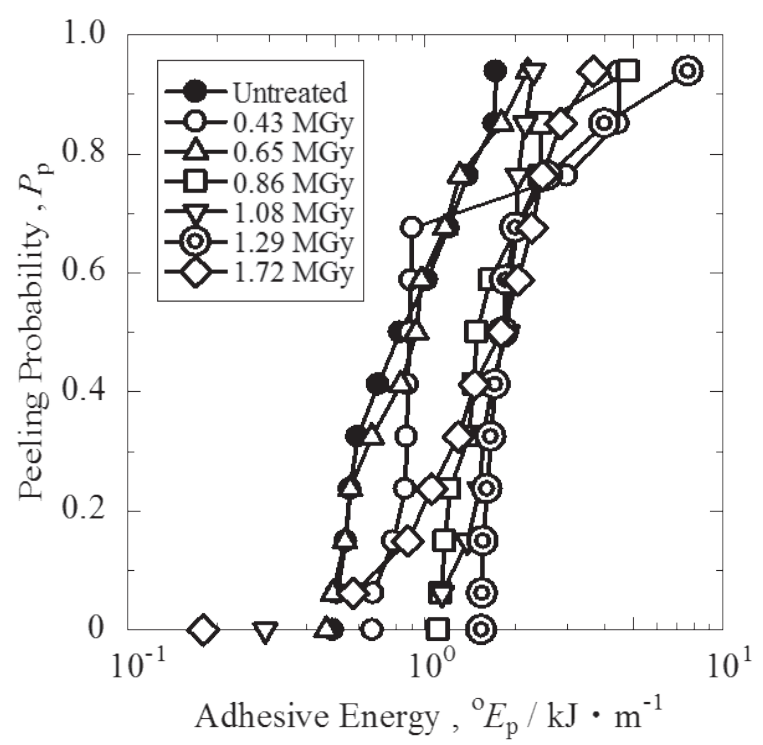

Fig. 4 Relationships between ${ }^{\circ} E_{\mathrm{p}}$ and $P_{\mathrm{p}}$ of PU/PET laminated sheets untreated and HLEBI-treated.

$1.89 \mathrm{~kJ} \cdot \mathrm{m}^{-1}$. $1.08 \mathrm{MGy}-\mathrm{HLEBI}$ samples are about 1.1 times of untreated samples. All ${ }^{\circ} E_{\mathrm{p}}$ values of PU/PET laminated sheets with small dose of 0.43 to 1.29 MGy apparently exceed all corresponding values of untreated samples. Thus, adhesion of PU/PET laminated sheets with small dose from 0.43 to 1.29 MGy-HLEBI deems effective.

\section{Discussion}

\subsection{The statistically lowest adhesive energy}

In order to obtain the statistically lowest peeling stress for safety design, the lowest ${ }^{\circ} E_{\mathrm{p}}$ value at $P_{\mathrm{p}}=0\left(E_{\mathrm{s}}\right)$ is assumed to be attained from the adaptable relationship of the 3-parameter Weibull equation iterating to the high correlation coefficient $(E)$. The $P_{\mathrm{p}}$ depends on the risk of rupture $\left(\left[{ }^{\mathrm{o}} E_{\mathrm{p}}-E_{\mathrm{s}}\right] /\right.$ $E_{\text {III) }}{ }^{6,21-27)}$

$$
P_{\mathrm{p}}=1-\exp \left[-\left(\left[{ }^{\mathrm{o}} E_{\mathrm{p}}-E_{S}\right] / E_{\mathrm{III}}\right)^{m}\right]
$$

The linear relationship can be converted from eq. (6), as follows.

$$
\ln \left[-\ln \left(1-P_{\mathrm{p}}\right)\right]=m \ln \left[\left({ }^{\mathrm{o}} E_{\mathrm{p}}-E_{s}\right) / E_{\mathrm{III}}\right]
$$

In predicting the $E_{\mathrm{S}}$, coefficient $(m)$ and constant $\left(E_{\mathrm{III}}\right)$ are the key parameters. When the term $\ln \left[-\ln \left(1-P_{\mathrm{p}}\right)\right]$ is zero, $P_{\mathrm{p}}$ is 0.632 and $\left({ }^{\circ} E_{\mathrm{p}}-E_{\mathrm{s}}\right)=E_{\mathrm{III}}$. The $E_{\mathrm{III}}$ value is determined, when the ${ }^{\circ} E_{\mathrm{p}}$ value at $P_{\mathrm{p}}=0.632\left({ }^{\circ} E_{\mathrm{p}}(0.632)\right)$ is equal to $\left(E_{\mathrm{III}}+E_{\mathrm{s}}\right)$ value. When $P_{\mathrm{p}}=0$, the required ${ }^{\circ} E_{\mathrm{p}}$ value to evaluate new structural materials is defined as the $E_{\mathrm{s}}$.

Figure 5 plots the iteration to obtain the highest correlation coefficient $\left(C_{\mathrm{c}}\right)$ with respect to the potential adhesive energy of peeling ${ }^{\circ} E_{\mathrm{s}}$ value $\left({ }^{e} E_{\mathrm{s}}\right)$ estimated from the logarithmic form.

Figure 6 illustrates the linear relationships between $\ln \left({ }^{\circ} E_{\mathrm{p}}-E_{\mathrm{s}}\right)$ and $\ln \left[-\ln \left(1-P_{\mathrm{p}}\right)\right]$. The values of $E_{\mathrm{III}}$ and $m$ are determined by the least-squares best fit method. The $m$ value is estimated by the slope of the relationship when ${ }^{e} E_{\mathrm{s}}=E_{\mathrm{s}}$.

Figure 7 shows $E_{\mathrm{s}}$ is always lower than the experimental ${ }^{\circ} E_{\mathrm{p}}$ value. The HLEBI $0.43,0.86$ and $1.29 \mathrm{MGy}$ improves the

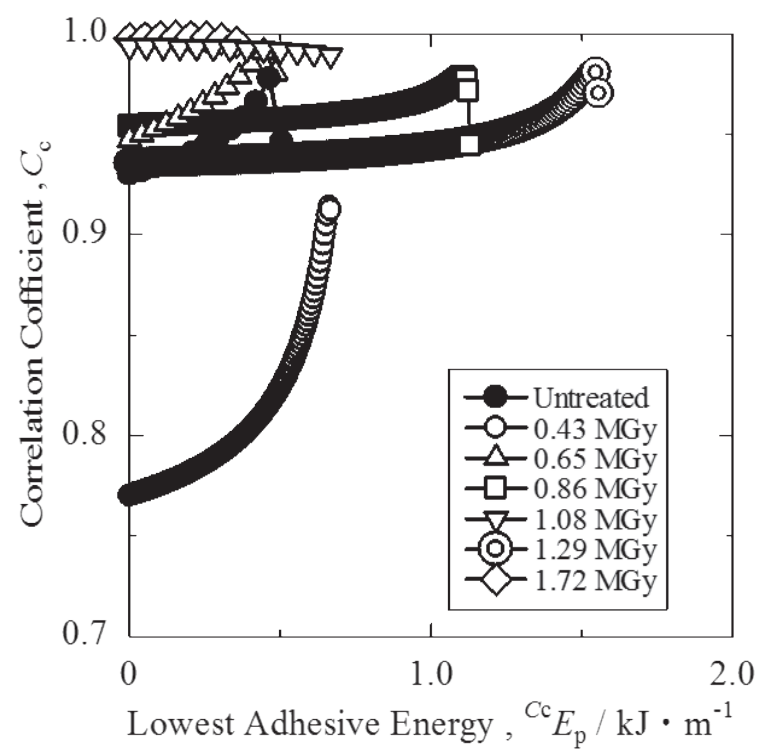

Fig. 5 Changes in correlation coefficient $\left(C_{\mathrm{c}}\right)$ of eq. (1) against the potential ${ }^{\mathrm{o}} E_{\mathrm{s}}$ value $\left({ }^{\mathrm{e}} E_{\mathrm{s}}\right)$ for PU/PET laminated sheets at each absorbed dose of HLEBI.

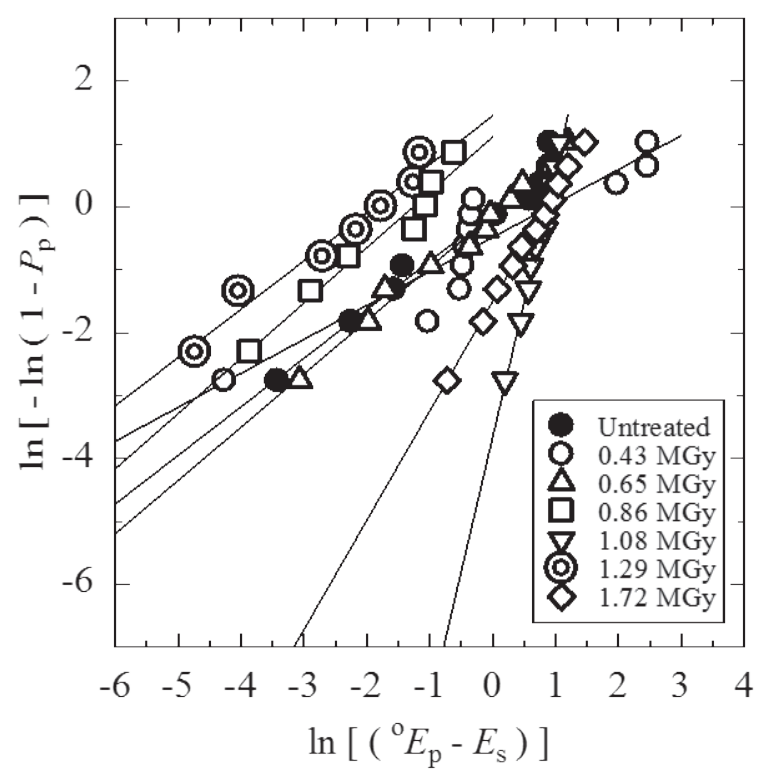

Fig. 6 Liner relationships between $\ln \left[-\ln \left(1-P_{\mathrm{p}}\right)\right]$ and $\ln \left({ }^{\circ} E_{\mathrm{p}}-E_{\mathrm{s}}\right)$ for PU/ PET laminated sheets at each absorbed dose of HLEBI.

$E_{\mathrm{S}}$ values of PU/PET laminated sheets over that of the untreated. The 1.29 MGy-HLEBI apparently enhances the $E_{\mathrm{s}}$ from $0.51 \mathrm{~kJ} \cdot \mathrm{m}^{-1}$ for the untreated to $1.55 \mathrm{~kJ} \cdot \mathrm{m}^{-1}$; as well as at low $P_{\mathrm{p}}$ of 0.06 (the lowest experimental ${ }^{\circ} E_{\mathrm{p}}$ ) from $0.51 \mathrm{~kJ} \cdot \mathrm{m}^{-1}$ for the untreated to $1.56 \mathrm{~kJ} \cdot \mathrm{m}^{-1}$. Consequently, HLEBI enhances the safety level (reliability) of PU/PET laminated sheets. This indicated HLEBI induced adhesion can be applied to practical articles with sterilization without volatilization, when the adhesive energy of peeling resistivity is less than $1.55 \mathrm{~kJ} \cdot \mathrm{m}^{-1}$.

\subsection{X-ray photoelectron spectrometry (XPS) of PU and PET surface}

Figures 8 and Fig. 9 show fracture surface analysis by 


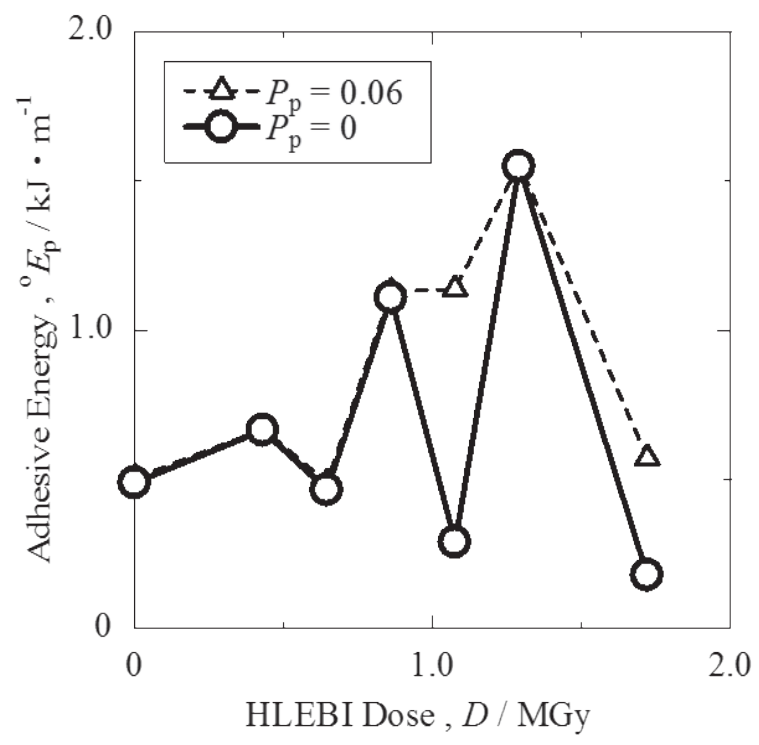

Fig. 7 Changes in the lowest adhesive energy $\left(\bigcirc: E_{\mathrm{s}}={ }^{\circ} E_{\mathrm{p}}\right.$ at $\left.P_{\mathrm{p}}=0\right)$ calculated for PU/PET laminated sheets against HLEBI dose to PET, together with experimental ${ }^{\circ} E_{\mathrm{p}}$ at low- $P_{\mathrm{p}}$ of 0.06 .

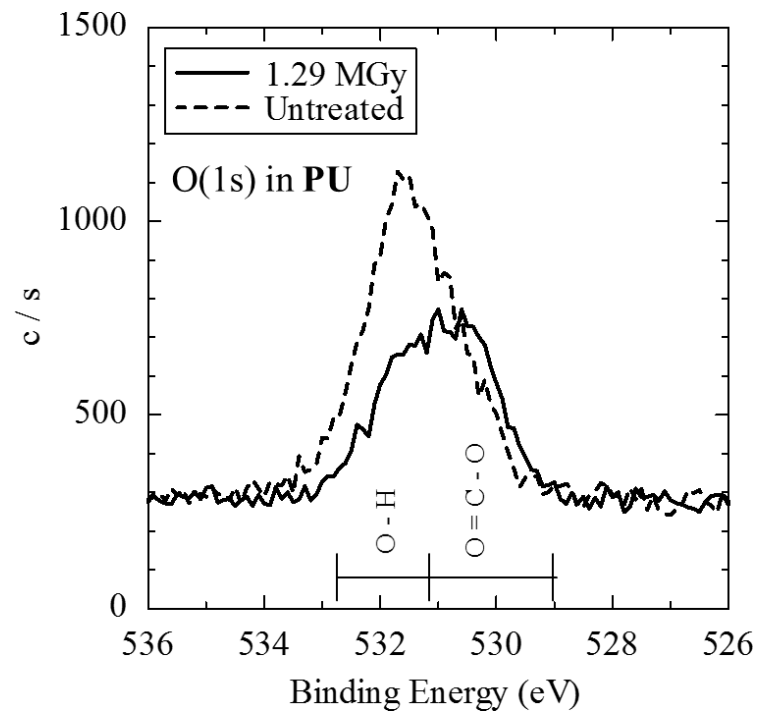

Fig. 8 Oxygen (1s) signal signals on PU side peeled surface from XPS analysis PU/PET laminated sheets with and without 1.29 MGy HLEBI.

X-ray photoelectron spectrometry (XPS) of oxygen (O (1s)) signals of the peeled on PU and PET films surface with and without 1.29 MGy HLEBI from PU/PET laminated sheets. Results indicate the HLEBI acts to make adhesion in the PU/ PET laminated sheets where fracture generally occurred near the peeled PU-PET interface.

In Fig. 8 the XPS narrow scan of $\mathrm{O}(1 \mathrm{~s})$ of the peeled 1.29 MGy sample on PU surface shows peaks at 531 and $531.5 \mathrm{eV}$ corresponding with the $\mathrm{O}(1 \mathrm{~s})$ in $\mathrm{O}=\mathrm{C}-\mathrm{O}$ and $\mathrm{O}-\mathrm{H}$ groups. In order to calibrate the results in detail, XPS signals of $\mathrm{C}$ have been obtained for PU with and without HLEBI (solid and broken lines in Fig. 8). The highest intensity of $\mathrm{O}-\mathrm{H}$ signal for untreated PU is gotten. As shown in Fig. 8, 1.29 MGy-HLEBI cut the O-H, whereas it remarkably enhances the $\mathrm{O}=\mathrm{C}-\mathrm{O}$ intensities, as shown in Fig. 1.

In Fig. 9 the XPS narrow scan of $\mathrm{O}(1 \mathrm{~s})$ of the peeled

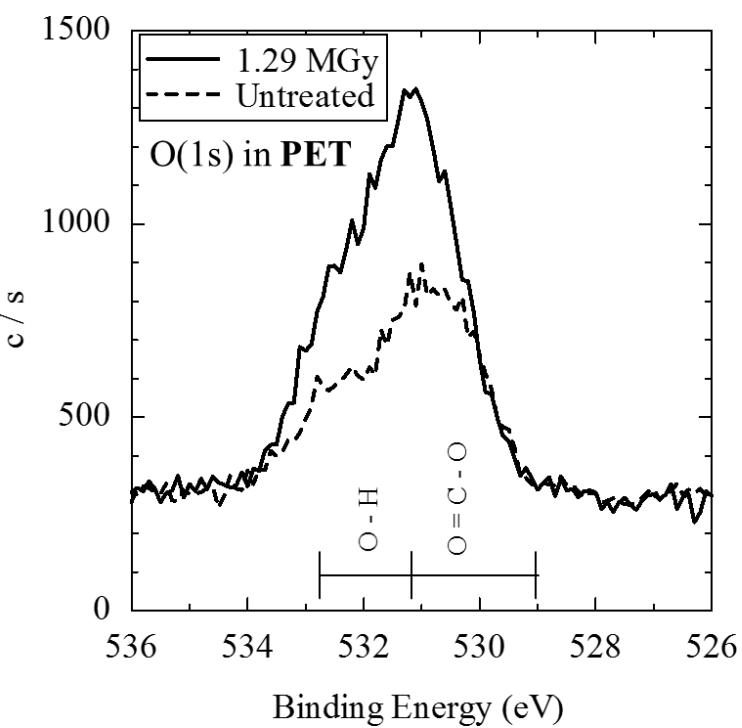

Fig. 9 Oxygen (1s) signals on PET side peeled surface from XPS analysis PU/PET laminated sheets with and without 1.29 MGy HLEBI.

1.29 MGy sample shows peaks at $531 \mathrm{eV}$ corresponding with the $\mathrm{O}(1 \mathrm{~s})$ in $\mathrm{O}=\mathrm{C}-\mathrm{O}$ group. In order to calibrate the results in detail, XPS signal of $\mathrm{O}(1 \mathrm{~s})$ in $\mathrm{O}=\mathrm{C}-\mathrm{O}$ have been obtained for PET with and without HLEBI (solid and broken lines in Fig. 9). The intensity of $\mathrm{O}=\mathrm{C}-\mathrm{O}$ peak of $1.29 \mathrm{MGy}-\mathrm{HLEBI}$ PET film after lamination (solid line in Fig. 9) is higher than that of untreated PET sheet after lamination (broken line in Fig. 9). It is explained that HLEBI activates the PET surface. The active PET attracts the oxygen atoms from atmospheric molecules or PU with increasing oxygen content.

On the contrary, the active PU easily adheres the PET with decreasing the oxygen content at PU surface. Based on the both reaction, the adhesive energy was increased. Therefore, residual PET deposition is apparently found on the PU film induced by inter-matrix fracture of PET. This can be explained by the adhesion energy from cross-linking between PU/PET being stronger than the cohesive energy of PET itself.

\section{Conclusions}

2-layer Polyurethane (PU) and Polyethylene Terephthalate (PET) (PU/PET) laminated sheets were prepared by a new adhesion method, a double-step treatment consisting of applying low dose ( $\leqq 1.72 \mathrm{MGy}$ ) of homogeneous low energy electron beam irradiation (HLEBI) prior to hot-press under $3 \mathrm{MPa}$ at $348 \mathrm{~K}$. Although the weak adhesion of 2-layer laminated PU/PET laminated sheets without our double-step treatment with hot-press after HLEBI had been observed, the strong adhesion of the PU/PET laminated sheets was found from the new double-step treatment applying low dose $\leqq 1.72$ MGy-HLEBI of the 2-layer assembled PU/PET prior to hot-press lamination under $3 \mathrm{MPa}$ at $348 \mathrm{~K}$.

(1) The double-step treatment applying increased HLEBI dose from 0.43 to $1.72 \mathrm{MGy}$ prior to hot-press enhanced the adhesive energy of peeling resistance $\left({ }^{\circ} E_{\mathrm{p}}\right)$ at peeling probability $\left(P_{\mathrm{p}}\right)$ of $0.06,0.50$ and 0.94 .

(2) Based on the 3-parameter Weibull equation, the lowest 
${ }^{\circ} E_{\mathrm{p}}$ value at the lowest $P_{\mathrm{p}}$ of zero $\left(E_{\mathrm{s}}\right)$ could be estimated. The double-step treatment applying HLEBI up to 1.29 MGy prior to hot-press apparently improved the $E_{\mathrm{s}}$. The maximum $E_{\mathrm{s}}$ value of the PU/PET laminated sheets with hot-press after 1.29 MGy-HLEBI dose was $7.65 \mathrm{~kJ} \cdot \mathrm{m}^{-1}$. Consequently, the double-step treatment of applying 1.29 MGy-HLEBI prior to hot press improved the safety level.

(3) The maximum peeling adhesive energy value at low $P_{\mathrm{p}}$ (zero and 0.06) of the laminated sheet irradiated at 1.29 MGy were 1.55 and $1.56 \mathrm{~kJ} \cdot \mathrm{m}^{-1}$, respectively. However, the higher dose of the double-stop treatment applying more than 1.72 MGy HLEBI apparently reduced the ${ }^{\circ} E_{\mathrm{p}}$ at each $P_{\mathrm{p}}$. Therefore, with careful consideration to dose level, the double-step treatment applying HLEBI prior to hot-press proves a useful method for strong and quick lamination of PU and PET with sterilization without the use of glue.

(4) Based on the XPS results, the residual PET deposition is apparently found on the PU film induced by inter-matrix fracture of PET. This can be explained by the adhesion energy from cross-linking between PU/PET being stronger than the cohesive energy of PET itself.

\section{Acknowledgements}

The authors wish to thank Prof. Akira Tonegawa of Tokai University for his useful help. Our sincere gratitude also goes to Eye Electron Beam Co, Ltd. (Gyoda, Saitama, Japan) for their support with this work.

\section{REFERENCES}

1) C.E. Santo, N. Taudte, D.H. Nies and G. Grass: Appl. Environ. Microbiol. 74 (2008) 977-986.

2) K. Oguri, N. Iwataka, A. Tonegawa, Y. Hirose, K. Takayama and Y. Nishi: J. Mater. Res. 16 (2001) 553-557.

3) M. Faudree and Y. Nishi: Trans. JIM 53 (2012) 1412-1419.

4) A. Oshima, H. Nagai, F. Muto, T. Miura and M. Washio: J. Photopolym. Sci. Tech. 19 (2006) 123-127.
5) M. Żenkiewicz: Int. J. Adhes. Adhes. 24 (2004) 259-262.

6) Y. Nishi, M. Uyama, H. Kawazu, H. Takei, K. Iwata, H. Kudoh and K. Mitsubayashi: Trans. JIM 53 (2012) 1657-1664.

7) Y. Nishi, H. Kawazu, H. Takei, K. Iwata, H. Kudoh and K. Mitsubayashi: Trans. JIM 52 (2011) 1943-1948.

8) C. Kubo, T. Okada, M. Uyama, M. Kanda and Y. Nishi: Trans. JIM 55 (2014) 1742-1749.

9) R. Suenaga, M. Kanda, N. Hironaka and Y. Nishi: J. Japan Inst. Metals 72 (2008) 35-38.

10) T. Shimaru: Tech. on Adhesion \& Sealing 3 (1959) 121-130.

11) D. Guyomar, K. Yuse, P.-J. Cottinet, M. Kanda and L. Lebrun: J. Appl. Phys. 108 (2010) 114910.

12) M. Kanda, K. Yuse, B. Guiffard, L. Lebrun, Y. Nishi and D. Guyomar: Trans. JIM 56 (2015) 2029-2033.

13) M. Kanda, K. Yuse, B. Guiffard, L. Lebrun, Y. Nishi and D. Guyomar: Trans. JIM 53 (2012) 1806-1809.

14) Y. Miyazawa, M. Uyama, S. Ishii, M. Kanda and Y. Nishi: Trans. JIM 54 (2013) 1166-1170.

15) M. Seno, K. Kurita, S. Yano and T. Sawaguchi: Basic Polymer Science (Kiso Koubunshikagaku in Japanese), (Kyouritsu Syuppan, Co., Ltd., 2000) pp. 128-129.

16) K. Oguri, K. Fujita, M. Takahashi, Y. Omori, A. Tonegawa, N. Honda, M. Ochi, K. Takayama and Y. Nishi: J. Mater. Res. 13 (1998) 33683371.

17) C. Kubo, A. Yagi, M. Kanda and Y. Nishi: Trans. JIM 56 (2015) 529533.

18) C. Kubo, M. Kanda and Y. Nishi: Trans. JIM 56 (2015) 1517-1522.

19) C. Kubo, M. Kanda, K. Miyazaki, T. Okada, M.C. Faudree and Y. Nishi: Trans. JIM 56 (2015) 1821-1826.

20) M. Kanda, K. Yuse, B. Guiffard, L. Lebrun, Y. Nishi and D. Guyomar: Trans. JIM 53 (2012) 1806-1809.

21) H. Takei, M. Salvia, A. Vautrin, A. Tonegawa and Y. Nishi: Trans. JIM 52 (2011) 734-739.

22) K. Iwata and Y. Nishi: Trans. JIM 49 (2008) 2058-2062.

23) Y. Nishi, H. Kobayashi and M. Salvia: Trans. JIM 48 (2007) 19241927.

24) N. Tsuchikura, M.C. Faudree and Y. Nishi: Trans. JIM 54 (2013) 371379.

25) H. Takei, K. Iwata, M. Salvia, A. Vautrin and Y. Nishi: Trans. JIM 51 (2010) 2259-2265

26) W. Weibull: Ingeniörs vetenskaps akademien, nr. 153 (Generalstabens litografiska anstalts förlag, Stockholm, 1939) pp. 16-22.

27) Y.P. Yampolskii: Russ. Chem. Rev. 76 (2007) 59-78. 